International Journal of Applied Linguistics \& English Literature

ISSN 2200-3592 (Print), ISSN 2200-3452 (Online)

Vol. 1 No. 5; September 2012 [Special Issue on General Linguistics]

\title{
Second Language Acquisition at the Phonetic-Phonological Interface: A proposal
}

\author{
Ashima Aggarwal (Corresponding author) \\ Department of Linguistics, University of Florida \\ 4131 Turlington Hall, PO Box 115454 \\ Gainesville FL 32611-5454 \\ E-mail: aaggarwal@ufl.edu
}

Received: 30-06- 2012

Accepted: 24-08- 2012

Published: 03-09- 2012

doi:10.7575/ijalel.v.1n.5p.208

URL: http://dx.doi.org/10.7575/ijalel.v.1n.5p.208

Publication of this article was funded in part by the University of Florida Open-Access Publishing Fund

\begin{abstract}
This paper examines the acquisition of novel second language phonological contrasts by speakers of different languages. It explores the possibility of building a framework to test the adult acquisition of voicing and aspiration features of Hindi by speakers of Dimasa, Rabha, Tamil and English. It is noteworthy that Hindi has a four-way voicing contrast while Dimasa, Rabha and Tamil have two-way, three-way and one-way respectively. The paper presents an experiment designed to test the acquisition of non-native acquisition by these L1 speakers. The task designed to train these L1 speakers to perceive the new contrasts is an AX same or different task. Training will be followed by retention and generalizability test also. Evidence of significantly better perception post-training will suggest access to Universal Grammar beyond the Critical period.
\end{abstract}

Keywords: Second language acquisition, Critical period, voicing contrast, Universal Grammar

\section{Introduction}

Although first language acquisition has been shown to be successful and effortless this is not the case with second language acquisition, especially for adults. In addition to this, second language acquisition differs from first language acquisition in that L2 acquisition might not always be complete. Both L1 and L2 are affected by a number of factors such as universal developmental order, constraints on possible phonological structures, aptitude, attitude and input (Birdsong 1992). The interaction of these variables may result in differential success in attainment of a language. Especially for the domain of L2 phonology neuromuscular abilities are said to constrain the acquisition of sounds that require different articulatory habits rendering the fate of L2 phonological acquisition to somewhat lesser than native-like. (Scovel, 1981, Wode, 1989, 1992). Apart from the muscular dexterity, the role of L1 phonology has been considered inevitable when it comes to adult L2 acquisition (Flege 1987a,b, Flege and Munro, 1994).

Flege (1987a,b) claims that age-related accentedness is perceptually based. He uses Wode's (1993, 1994) termscontinuous mode and categorical mode of perception to elaborate this. Where continuous mode of perception lets one discriminate between the fine gradience in the degree of voicing say of $/ \mathrm{b} /$. The categorical mode permits the hearer to only perceive those cues that bring about a phonemic contrast between two sounds (e.g. /p/-/b/). Flege goes on to suggest that children begin with a continuous mode of perception, but as they begin to hear the contrastive phones of their language they tune their perception to slowly create the phonetic categories that belong to their native language. These listeners develop an affinity to perceive L2 sounds in terms of their L1 categories. Flege proposed that L2 phonetic categories that are perceived as similar to L1 categories are merged with them failing the construction of new phonetic categories for them. However, this does not rule out the possibility of new sound categories for a new language. It means that the learners will need to reactivate the continuous mode of perception by focusing on minute differences in Voice Onset Time (VOT) between L1 and L2 to form new phonetic categories. Maturational or psychological, the relationship between such constraints continues to challenge researchers till date.

Long (1990) claims the domain of phonology to be different from say syntax, semantics or morphology in that it is restricted by a very early critical period, 5-6 years of age. It is important to define the critical period here as 
International Journal of Applied Linguistics \& English Literature

ISSN 2200-3592 (Print), ISSN 2200-3452 (Online)

Vol. 1 No. 5; September 2012 [Special Issue on General Linguistics]

components GEN, EVAL and CON allow infinite outputs to be evaluated based on the language specific ranking on universal constraints. It would be questionable to claim then that something allows this ranking in the acquisition of L1 grammar but prevents it from happening for an L2.

Beyond accents, a critical period for L2 phonology would indicate that interlanguage phonology would show no development or changes in the ranking of constraints. In other words the learners have lost their ability to reset the parameters and will be limited to their L1 final ranking (assuming full access). The initial state and the end state of the L2 speaker would then be the same. The lack of reranking would in turn reflect inaccessibility to Universal Grammar (Chomsky, 1995) or accessibility to UG only via the L1. UG assumes that there exists a set of abstract principles that is present in all of the world's natural human languages (Chomsky 1995). In terms of Optimality Theory, a critical period means that the L2 learners do not have access to UG constraints anymore and their interlanguage grammar is not constrained by UG.

Moving beyond the omnipresent L2 accent, Young-Scholten and Archibald (2000) in their review of L2 syllable structure seek to answer whether L2 syllable are constrained by allowable L1 syllable structures. They found that not only are sounds of a language transferred but there is also evidence that learners attempt to maintain their L1 syllable structure (there is transfer from L1). Thus, L2 syllable structure is in part shaped by native language. Finally, in terms of ultimate attainment the existence of critical period for phonology denies any learnability post puberty and hence never the possibility of native-like speech perception and production. Such a claim would deny the mechanisms of Optimality theory such as Constraint Demotion Algorithm (Tesar \& Smolensky, 2000) and Gradual Learning Algorithm that are error driven mechanisms for L2 learning (Boersma 1997; Boersma \& Hayes 1999, 2001). A detailed description of these two will be provided in a later section of this paper.

\subsection{Counter-evidence to critical period for phonology}

On the contrary there is an emerging literature on the ultimate attainment in adult learners (White 2000, 2003, Swartz and Sprouse 1996) and possibly access to UG by adult L2 learners (Birdsong 1992, Young-Scholten 1994, Ioup 1989, White \& Genesee 1996). In their studies on phonological acquisition in adulthood, Bongaerts, Planken, and Schils (1995) and Bongaerts et.al.(1997) have shown that late learners can achieve native-like performance. To illustrate one of his study, Bongaerts (1999) looked at 41 native English subjects and 41 native Dutch speaking subjects who had not been exposed to English until age 12yrs. Both the groups were given a read allowed task that was judged by naïve native speakers of English for speakers exposed to English after age 12 on four different read aloud tasks were rated for authenticity. Results showed that 5 out of 41 Dutch participants were rated within 1.2 standard deviations of the mean for native English group. In a similar study on restrictions on French liaison using reading-aloud tasks conducted by Birdsong (1997), one fifth of the participants (adults) performed correctly, without any errors, thus exhibiting this complete acquisition of liaison.

Klein (1995) also argued that absolute biological barriers for adult perception and production do not exist. What is necessary is massive and continued access to L2 input. He argued that this is possible if the learner has very high level of motivation which arises from their need to sound like a native speaker of that language.

Recently more light was shed on the amount and quality of input that is needed for successful L2 acquisition by Rothman and Guijarro-Fuentes (2010). They claim that L2 acquisition takes place in the classroom and outside with a much lesser amount of input than that in naturalistic setting. This could be said to attribute to the native-non native differences in acquisition, but the generative paradigm suggests otherwise. I quote 'Since within the generative paradigm linguistic properties are not acquired from direct evidence from the input, so-called poverty-of-the-stimulus properties, but as a result of linguistic universals that are triggered via the acquisition of properties encoded in the language-specific lexicon of the environment, equal quantity of input would not be needed'. Rothman and Guijarro-Fuentes (2010) suggest what is required is 'minimally sufficient' input that provides the triggers for the system to be configured although the definition of minimally sufficient input is debatable and beyond the scope of this paper.

Schneiderman and Desmarais (1988) reported that their two native English subjects who acquired many languages in adulthood were judged as belonging to French-speaking areas by native Francophones, who listened to short tape-recordings of interviews of these subjects. One of the two subjects could also pass as a native speaker of Spanish. In another study by Novoa, Fein and Oblet (1988) a native English subject C.J. who acquired French, German, Italian, Moroccan Arabic and Spanish after the age of 15 was judged as having a lack of foreign accent. Finally Ioup (1989) reported on the success of their two subjects Julie and Laura (native-english speakers) in acquiring Egyptian Arabic as adults. They were described as native speakers by 8 out of 13 judges.

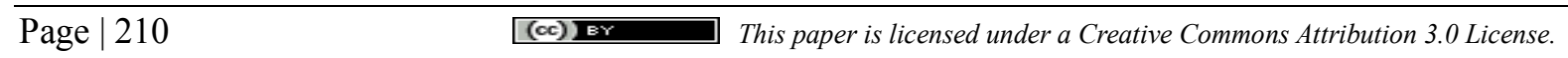


International Journal of Applied Linguistics \& English Literature

ISSN 2200-3592 (Print), ISSN 2200-3452 (Online)

Vol. 1 No. 5; September 2012 [Special Issue on General Linguistics]

The results of such studies would provide challenge to Scovel's (1981) assertion that there exists a maturationally constrained time frame for acquisition of accent, ending around 12 years of age, beyond which it is impossible for learners to acquire such a good pronunciation in a non-native language that they can 'pass themselves off as native speakers' of that language (Scovel, 1988).

The fact that in most of the studies that show native-like successful acquisition of linguistic properties by adult learners, the percent of such learners constitute $5-20 \%$ of the subject population cannot be ignored. This shows that possibility of late learning is not just accidental but highly relevant to the study of L2 acquisition as it related to the critical period (cf. Bley-Vroman, 1989; Selinker, 1972). Thus, a great chunk of literature undermines the role of critical period as it relates to phonology.

\section{Task for the L2 learner}

The task for the learners from an OT perspective would then be to arrive at the L2 Hindi ranking for Voicing and aspiration in stop consonants in the word initial position. For this they must recognize the underlying forms and the ranking of constraints that lead to correct surface forms for the target language. Within this theoretic framework, the speakers of various L1s- Rabha, Dimasa, Tamil are expected to arrive at the Hindi ranking by the use of two mechanisms- the Constraint Demotion Algorithm abbreviated CDA (Tesar and Smolensky 2000) and the Gradual Learning Algorithm abbreviated GLA (Boersma 1997; Boersma \& Hayes 1999, 2001).

\subsection{Constraint Demotion Algorithm:}

It begins with all the constraints being unranked. Then given the optimal surface forms of the language the role of the algorithm is to figure out the language exclusive ranking. The learner matches the winning candidate to the all the remaining non-winning candidates. The loser must be dominated by some other constraint that is higher ranked. All the constraints that the optimal output violates are less strict and violable and are thus demoted minimally below the highest constraint that would eliminate the loosing candidate. The CDA does not reflect the different interlanguage stages of learning because the shift to the adult grammar is almost immediate.

Table 1. A sample table below shows how CDA works

\begin{tabular}{|l|l|l|l|l|}
\hline & $\mathrm{C} 1$ & $C 2$ & $C 3$ & $C 4$ \\
\hline$y$ & & $*$ & $*$ & \\
\hline $\operatorname{b} x$ & & & & $*$ \\
\hline
\end{tabular}

The winning candidate $\mathbf{x}$ violates constraints $\mathrm{C} 2$ and $\mathrm{C} 3$ while the sub-optimal candidate $\mathbf{y}$ violates $\mathrm{C} 4$. Initially all the constraints $\mathrm{C} 1, \mathrm{C} 2, \mathrm{C} 3, \mathrm{C} 4$ were unranked. In response to the input, $\mathrm{C} 2$ is minimally demoted below $\mathrm{C} 4$ (the constraint that rules out $\mathbf{y})$ yielding $(\mathrm{C} 1, \mathrm{C} 3, \mathrm{C} 4)>>\mathrm{C} 2$ and $\mathrm{C} 3$ is demoted minimally below $\mathrm{C} 4$ giving $(\mathrm{C} 1$, C4) $\gg(\mathrm{C} 2, \mathrm{C} 3)$. This gives us the ranking where the constraints violated by the winner are lower ranked than those violated by the non-winning candidates.

\subsection{The Gradual Learning Algorithm}

Boersma (1998) proposes stochastic constraint ranking, that is, the ranking of constraints is not absolute of fixed instead based on probability. Given such a mechanism one can explain how the same given input might have different possible outputs even though one output might be more probable than the others. All the constraints in a person's grammar begin with the arbitrary value of 100 . Each constraint is thus associated with a probability density function whose center lies at its ranking value. The evaluation is non-deterministic, and the strict domination of the language-specific constraints is reflected by the space between the constraints. In other words each constraint has a range of values it can select from at the time of evaluation (production or perception). At this time of evaluation, if the value of two constraints selected by the listener overlaps, it will lead to free variation and for a perception grammar it implies that the listener will alternate between listening two phonetic forms. On the other hand if the values selected for the two constraints are far apart then the ranking of constraints is relatively strict and the listener will always hear one phonetic form and not the other. This will happen if the input does not have much variation. That is, if the input data is not varied then the constraint values will be far apart and fixed.

Whenever a listener hears a target language input, he/she tries to match the ranking values of the target form and his/her form. If they do not match then the listener increases the values (and thereby the strictness) of all 
International Journal of Applied Linguistics \& English Literature

ISSN 2200-3592 (Print), ISSN 2200-3452 (Online)

Vol. 1 No. 5; September 2012 [Special Issue on General Linguistics]

constraints that allow the listeners form and decreases the values of the constraints that allow the target form.

The Gradual Learning Algorithm can also describe the stages of acquisition, unlike CDA. Curtin (2001) uses GLA to model the variation in children's production and their stepwise changes in grammar using an orderly demotion of markedness constraints thereby resulting in the acquisition of adult-like prosody.

An advantage of the GLA is that it can help establish the can learn rates of variation because contradictory options exert contrasting effect on ranking values. This learning also relies on frequency in that the more frequently heard (in training trials) variant gets relevant ranking values of the interacting constraints. Eventually the difference in frequency of conflicting inputs will get the constraint values separated so far apart that the ranking will be fixed.

Then for this study the various L1 learners should begin with a ranking of their L1 constraints and UG, assuming Full Transfer and Full Access (Schwartz and Sprouse, 1996). Initially faithfulness constraints are demoted below markedness that is followed by subsequent reranking within the markedness constraints followed by the promotion of faithfulness constraints above markedness once again (Hancin- Bhatt, 2008). Boersma and Escudero (2003) have successfully used phonetically based phonological constraints to portray the perception grammar of Canadian English and Canadian French learners using GLA. They make use of 'optimal perception hypothesis' that states that an optimal listener will select auditory properties that consistently distinguish sounds in the production of his/her language. On top, such a hearer is likely to perceive the intended sounds by the speaker. Thus the stimuli used in the training should help the listeners, on the basis of frequency, establish the constraint ranking that allows them to hear all four voicing and aspiration contrasts.

\section{Considering two opposing views}

The no parameter resetting view suggests that speakers can resort to only those parameter settings in their interlanguage that are present in their L1. This view suggests that any subsequent parameter resetting is not possible in response to L2 input, which means that new parameter values cannot be acquired. This implies that native like representations like those of speakers of L2 will definitely be unattainable if the L1 and L2 have different parameter values. No parameter resetting then infers that there is full transfer but not full access. An interlanguage grammar based on no parameter resetting would mean that there would be no change in the learner's representations subsequently. The representations will remain same, as they were initially, namely L1 based (White 2003).

The opposing position to the no parameter resetting is the 'parameter setting and resetting' position. This assumes that the interlanguage grammar of the learner is fully constrained by UG. The learners' grammar can then draw from universal grammar even what was not present in their L1. Assuming a full Transfer Full access view, the initial state would consist of L1 parameter settings with the possibility of being reset in response to the properties of the L2 input (Schwartz and Sprouse 1994, 1996). Unlike no-parameter resetting hypothesis, the initial and subsequent stages within the interlanguage grammar will be different if the L1 and L2 have different parameter values.

Assuming the alternative approach, Full Access No transfer supports that L1 is never present in the interlanguage grammar, that is, it does not form a part of the interlanguage grammar at the initial stage or at subsequent stages. Instead the parameters are set to L2 values right away from the beginning. This is possible because the learners have access to UG that in turn interacts with the incoming input from L2 sans a preceding L1-setting stage. This suggests that there is parameter setting, like in the case of L1 acquisition, but no need for resetting (White, 2003).

Thus the Full transfer full access and Full Transfer without access agree in that restructuring of parameter values and hence attainment of L2 parameter values is possible, where they differ is the issue whether L1 settings are ever transferred or not. At the same time they disagree with the 'no parameter hypothesis' that disallows any resetting during the course of L2 development.

If it is assumed that no-resetting is possible in the case of the L1 learners involved in this study, namely, Dimasa, Rabha and Tamil, then it should be found through the perception test that the speakers are incapable of perceiving the contrast missing in their L1. In other words, the Tamils should not be able to perceive anything other than plain voiceless stops, the Dimasas should not be able to perceive Voiceless stops and Voiced aspirated stops and the Rabhas should never be able to perceive Voiced aspirated stops from Hindi, irrespective of the type of training or the stimuli used. 
International Journal of Applied Linguistics \& English Literature

ISSN 2200-3592 (Print), ISSN 2200-3452 (Online)

Vol. 1 No. 5; September 2012 [Special Issue on General Linguistics]

If it is assumed that resetting of parameters is possible then it can be claimed that the L2 learners can move beyond the settings of their L1 to adapt to new voicing and aspiration contrasts, even in adulthood. This stance is somewhat more appealing to me based on the existing theories and research that strengthen this claim.

\section{Methodology}

During the pretest, participants in all the groups are presented with 12 AXB triads (=36 words) of Hindi stops, 6 belonging to the bilabial and 6 belonging to velar place of articulation, that contrast in voicing or aspiration word initially. The sequence of presentation is counterbalanced within the different blocks presented to each listener (AAB, ABB, BBA, BAA). The tokens are alternated with equal number of distractors (12 AXB triads). This set is repeated two or three times ( $24 \mathrm{AXB}$ triads $\mathrm{X} 3=72$ triads) to ensure that the perception results are not accidental but based on some true phonological representation that the listeners are relying on. All the groups are tested on two inter stimulus intervals (ISI $=500 \mathrm{~ms}$ and ISI $=1500 \mathrm{~ms}$ ). So the 72 triads will be run twice for each listener, once with $\mathrm{ISI}=500 \mathrm{~ms}$ and once with $\mathrm{ISI}=1500 \mathrm{~ms}$ (so $72 \times 2=144$ triads). During the pretest, the participants are informed that each trial will consist of three words and that they are to say whether the second $(\mathrm{X})$ is more similar to the first $(\mathrm{A})$ or to the second (B). Note that $\mathrm{X}$ is physically different token of A or B so that listeners do not attend to acoustic differences that are not phonetically relevant in Hindi and instead focus on acoustic differences that differentiate phonetic categories in L2 Hindi.

\subsection{Training}

The training is same as pre-test except that this time we use an AX identification task instead of AXB forced-choice identification task. After each stimuli the listener presses a key on the keyboard that says 'same' or 'different'. After each response by the listener the computer screen gives feedback to them. This is done by means of a check mark (for correct answer) or a cross mark appearing (for wrong answer) on the computer screen after every. The stimuli repeats till the participants get the correct answer.

\subsection{Posttest}

On the third day the subjects take the posttest. The posttest will be same as the pre-test. Immediately after the posttest all the experimental groups take generalizability test.

\subsection{Generalizability test}

The stimulus for this test will contain 6 AXB pairs. These pairs consist of monosyllabic words that contain dentals in the onset position. Half of these pairs vary for voicing and the other half vary in aspiration. The will be alternated by 6 distractors, resulting in a total 12 AXB pairs. The generalizability test will be exactly same as the posttest except that the place of articulation will be Dental instead of bilabial or velar.

\subsection{Retention test}

After a period of two weeks the participants will be given the posttest again to see if they perform the same way or if there are any changes.

\section{Optimality theory as the optimal theory}

There are three conditions that are proposed by Hancin-Bhatt (2008) to be met in order for a theory to be adequate as a theory of acquisition. First, generalizability across the levels of phonology, accountability for the range of possible structures that occur in L2 sound patterns and predictability with respect to how an input will trigger the restructuring of the grammar (Also see Grosjean 1998 and White 2000). Hancin-Bhatt elaborates further that there are some fundamental issues that a theory of phonological acquisition needs to address. Foremost the theory must define what the assumed phonological features at the initial state are and in subsequent stages, second what the inputs and representations that force restructuring in the grammar are, and finally, how the grammar accommodates multiple grammatical representations for a single input. In the following discussion, I will show how OT fulfills all the criteria of a sound phonological theory as compared to other theories such as those proposed by Best (1995), Flege (1995), Major (2001).

Below is a brief overview of some models that seek to explain L2 acquisition.

Major's Ontogeny Phylogeny Model (OPM) intends to capture the patterns in interlanguage grammar and the relationship between L1, L2 and universals. He claims that 'L2 increases, L1 decreases, and U [universals] increases and then decreases.'

At the initial stage of learning the learner has only L1 and universals are accessible only through the L1. Although Major's OPM made predictions about the stylistic variations and linguistic relationships such as similarity and markedness it leaves a lot of questions unanswered. It leaves open the questions such as the working of the universals and the L1 and L2 systems. 
International Journal of Applied Linguistics \& English Literature

ISSN 2200-3592 (Print), ISSN 2200-3452 (Online)

Vol. 1 No. 5; September 2012 [Special Issue on General Linguistics]

Another model suggested to explain the perception of non-native lies in the seminal work by Catherine T. Best (1995) who proposed the Perceptual Assimilation Model (PAM). PAM suggests that L2 perception is greatly influenced by L1 phonological system and that the perception of non-native segments is performed on the basis of their being same-as or different-from the native phonological system (Best, 1995). According to the PAM a given non-native phone may be perceptually assimilated to the native phonological system in one of the six ways. First, Two-Category assimilation (TC) is where two non-native phones assimilate to two different native phones. Second, Single Category assimilation (SC) takes place when two non-native phones assimilate to the same L1 phone. Third, Category Goodness (CG) occurs when two non-native phones get assimilated to the same native phone but one of the non-native phones seems to fit better than the other. Next, Uncategorized-Categorized pair (UC) occurs if one non-native phone is categorized while the other remains uncategorized. However if both the non-native phones cannot be categorized, we have a condition called Uncategorized-Uncategorized pair (UU). Last, the non-native phones remain Non-Assimilable (NA) if the L2 sounds are perceived as non-speech sounds different from any native phonemes. Thus the PAM describes the assimilation of not individual sounds but sound contrasts of non-native language into that of L1.

To this end PAM is a suitable model to describe the assimilation possibilities of non-native to native phoneme categories but it might be inadequate to provide an acquisitional account of second language phonemes. In other words it does not describe how do listeners progress as the course of learning proceeds. PAM cannot be criticized as a model of acquisition per se since it meets the requirements of an adequate model as proposed by Hancin-Bhatt, but I suggest that it is does not provide an account of the learning process. It does not shed light on the resetting of parameters, speaking in strict UG terms.

In the discussion of various acquisitional theories the mention of Flege's SLM (1995) is quintessential. The SLM claims that the more different the L2 and the nearest L1 sound are, the more likely the learners will notice the dissimilarity between the two sounds. In other words, the L2 sounds that remain dissimilated are less challenging than the sounds that are strongly assimilated into L1 sounds According to Flege's SLM the sounds in one's L1 and L2 interact in two ways. First is "category assimilation" which means when a novel category cannot be instated for the L2 sound because they are always classified as examples of L1 sound, a new category for the L2 sound is not formed, instead, the L1 and the L2 sound 'merge' into one phonetic category over time. It is hypothesized that this merged category incorporates the phonetic characteristics of the two L1 and L2 sounds. In terms of voicing then an example could be a native speaker of French where $/ t /$ is represented by a short-lag VOT of about 20ms who learns English as his L2 where /t/ is realized by a long-lag VOT value of about $80 \mathrm{~ms}$ might develop a merged phonetic category of the two L1 and L2/t/ sounds producing the new merged / $t$ / with a VOT value of $60 \mathrm{~ms}$ (intermediate value of the L1 and L2). This new merged category will now be used by the speaker in both his L1 French and L2 English in the absence of two different categories for each language.

The second way in which the L1 and L2 phonetic systems are predicted to interact based on the SLM is called "phonetic category dissimilation". This occurs when the learner forms a new L2 category. Since bilinguals want to retain a contrast amongst all sounds present in their common L1-L2 phonetic area it causes the newly formed L2 category to dissimilate or move away from the nearest L1 sound. This is evident from a study conducted by Flege and Eefting (1987) that showed that English-Spanish bilinguals used longer VOT values for English voiceless stops and shorter VOT values for Spanish voiceless stops than their monolingual counterparts. This is evidence indicating that L1 Spanish voiceless stop categories somewhat dissimilated from the L2 English voiceless stop categories.

Again although I in no way want to undermine the work done by Flege but I suggest that for the purpose of this acquisitional study we need a framework that can model developmental sequence of the different L1 groups at the different stages of interlanguage grammar which does not suffice by the use of SLM.

Although the task for an adequate theory is by no means simple, nevertheless optimality theory has the elements to meet the requirements of a sound acquisitional theory.

A brief summary of OT follows, some of which has been mentioned in part in previous sections.

The advent of Optimality theory can be traced back to Prince and Smolensky (1993) as a move away from the derivational approaches to phonology. Similar to the derivational approach, the underlying mental representation and the surface representation of sounds still exist but now they are referred to as the input and the output respectively. Instead of rules now there are constraints. Archangeli (1999) provides a description of the way OT works. It has components called the GENerator, EVALuator and the CONstraints. The generator generates a set of candidates or prospective outputs that are evaluated by the evaluator on the basis of the least expensive

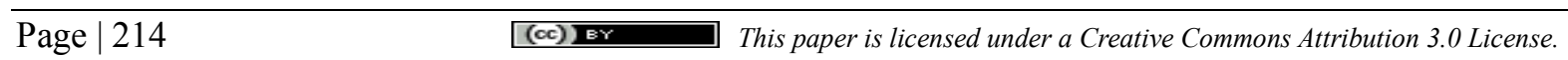




\section{International Journal of Applied Linguistics \& English Literature}

ISSN 2200-3592 (Print), ISSN 2200-3452 (Online)

Vol. 1 No. 5; September 2012 [Special Issue on General Linguistics]

violation incurred against the universal constraint set, thereby producing the optimal output candidate. In terms of OT, universal grammar is proposed as a set of universal constraints that are violable. The universality of these constraints themselves provides a means to explain the cross-linguistic similarities on one hand and the violability of these constraints explains language variation. OT is economical since it presents a single means to express which constraints are violable through strict domination of constraints unlike rewrite rules that were so many in number and ordered with respect to one another.

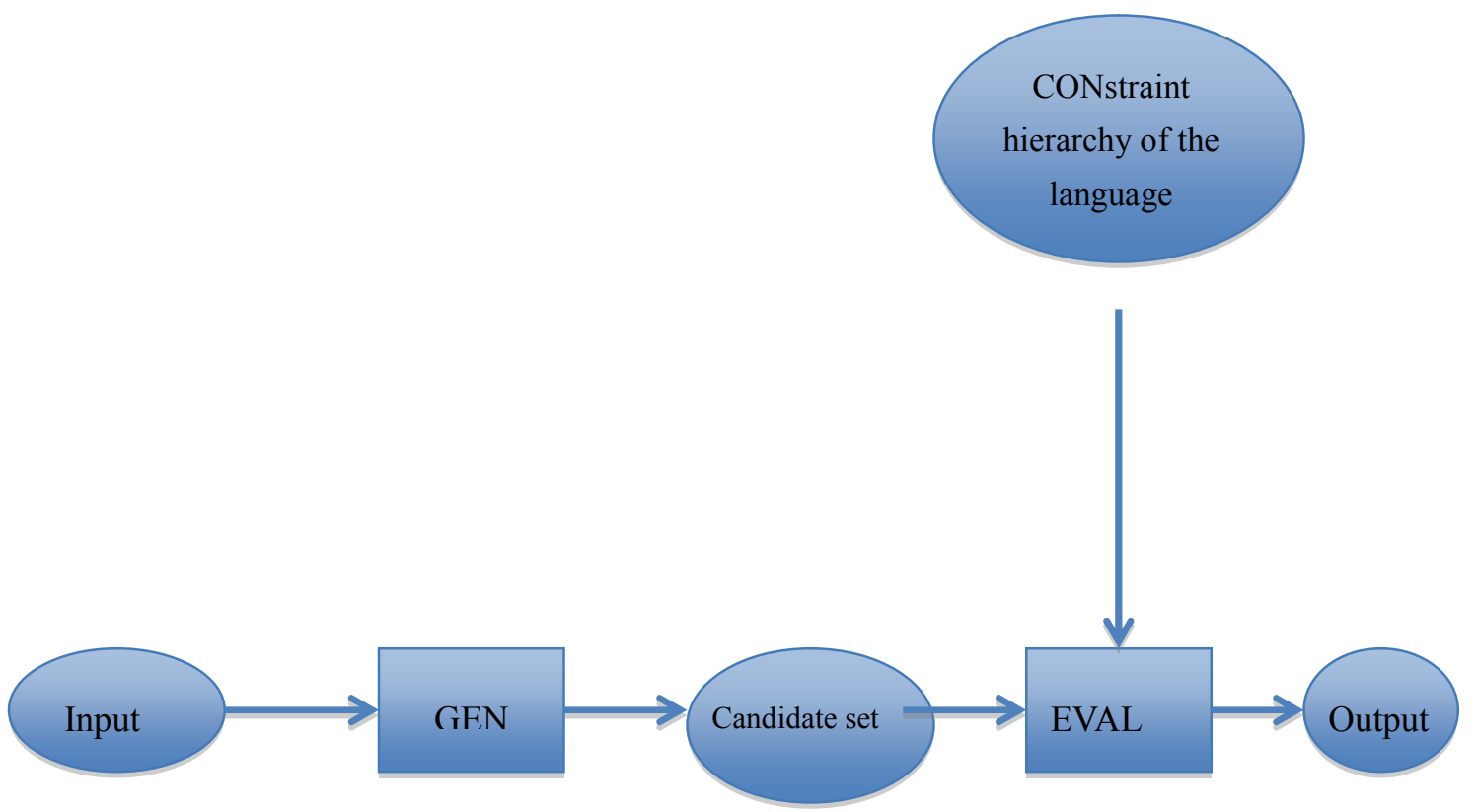

Figure1: Archangeli's schema of OT Source: Archangeli (1999)

The universal set of constraints belongs to either of the two classes: Markedness constraints or Faithfulness constraints. Markedness constraints ensure well-formedness by restricting marked structures in languages while faithfulness constraints allow preservation of input structure. Both types of constraints are violable and the winning candidate is the one that incurs least serious violations. The seriousness of the constraints is determined by how high the constraint is ranked in the hierarchy of that language.

Tableau 2. Example of Constraint ranking

\begin{tabular}{|l|l|l|l|}
\hline Input & Constraint 1 & Constraint 2 & Constraint 3 \\
\hline Candidate 1 & $* !$ & & \\
\hline Candidate 2 & & $*$ & \\
\hline C Candidate 3 & & & $*$ \\
\hline
\end{tabular}

In the above tableau the constraint ranking is strictly hierarchical

\section{CONSTRAINT 1 >>CONSTRAINT 2>> CONSTRAINT 3}

Since CONSTRAINT 1 is highest ranked, any violated will not be tolerated, CONSTRAINT 2 is the second most expensive constraint to be violated so candidate 2 is also ruled our so the optimal winner is candidate 3 which violates the lowest ranked constraint.

The rankings of constraints are language-specific and it is claimed that different constraint rankings will give rise to different language typologies. Thus there will be languages that use a different constraint ranking such as

CONSTRAINT 2>>CONSTRAINT $1>>$ CONSTRAINT 3 or 
International Journal of Applied Linguistics \& English Literature

ISSN 2200-3592 (Print), ISSN 2200-3452 (Online)

Vol. 1 No. 5; September 2012 [Special Issue on General Linguistics]

CONSTRAINT 1 $>>$ CONSTRAINT $3>>$ CONSTRAINT 2 that will lead to different optimal candidates for those languages. These different rankings also delimit the grammars of the world's languages unlike the large number of rules within derivational phonology.

An advantage of OT over the rule-based theory is its straightforwardness in explanation of the "homogeneity of target/heterogeneity of process' (McCarthy). Within A rule based theory, a rule describes the process and the change that applies to it. But there is no motivation why a number of processes apply to the same target over and over again. There is no explanation why the same target undergoes recurrent changes. Contrary to this OT, successfully explains the reason: to avoid the target from being marked, that is, the markedness constraints prevent the target from occurring as it is and therefore it need to undergo repairs. However, what repairs will take place resulting in the final output depends on the language specific ranking.

OT is capable of not just modeling learning but also describing the recourse during the interlanguage stages of grammar. It explains learnability using the CDA and the GLA. (The workings of the CDA and the GLA have been mentioned in the earlier sections so I will not repeat it here). The CDA describes how restructuring takes place and the GLA is efficient in explaining variability between learners in their developmental grammars using error-driven approaches.

Universality of the constraints, violability of the constraints and the different ranking of constraints in languages form the foundational pillars of explanatory adequacy in Optimality Theory. These functions and workings of the OT make the case for it to be the best suitable theory to describe acquisition. Where universal similarities in the world's grammars violability of constraints allows inter linguistic variation and different rankings explain typological variation among languages. This coupled with the Gradual learning algorithm can efficiently explain the $\mathrm{L} 2$ acquisition of novel second language properties or contrasts.

\section{Conclusion}

The results of this study bear great consequences in either supporting or refuting the existence of the critical period. A reranking of the existing L1 constraint hierarchy, as evidenced by the pretest, would indicate successful acquisitional capabilities even after puberty, defying the strict $\mathrm{CPH}$. However, the lack of any restructuring of the $\mathrm{L} 1$ constraint ranking will indicate the less severe nature of the critical period.

In either case the implications have serious consequences of L2 pedagogy. The need for unaccented and 'unimpaired' learning, which is the concern of most foreign language learners, relies on the strictness of this maturational barrier. The study will conclude whether it is possible to learn novel L2 sounds in adulthood or parents need to start early. The question of 'how early?' is yet beyond the scope of this project because of the varied definitions of the critical period proposed by different researchers.

\section{References}

Archangeli, D. (1999). Introducing Optimality Theory. Annual Review of Anthropology 28, 531-552.

Archibald, J. (1993a). Language learnability and L2 phonology. Dordrecht: Kluwer.

Best, C. T. (1995). A direct realist view of cross-language speech perception. In W. Strange (Ed.), Speech perception and linguistic experience. Issues in cross language research,171-204. Timonium, MD: York Press. Birdsong, D. (1992). Ultimate attainment in second language acquisition. Language, 68, 706-755.

Birdsong, D. (1997). Intransitivity and SE in French: Aspects of late L2 learnability. Paper presented at the 22nd Boston University Child Language Development Conference.

Bley-Vroman, R. 1989. "The Logical Problem of Foreign Language Learning". In S. Gass and J. Schachter (eds.) Linguistic Perspectives on Second Language Acquisition. Cambridge: Cambridge University Press, 41-68. Boersma, P. (1998). Functional phonology: Formalizing the interactions between articulatory and perceptual drives. Doctoral dissertation, University of Amsterdam.

Boersma, P. and Escudero, P. (2003): Modelling the perceptual development of phonological contrasts with Optimality Theory and the Gradual Learning Algorithm. In Arunachalam, Sudha, Elsi Kaiser and Alexander Williams (eds.) Penn Working Papers in Linguistics 8.1: Proceedings of the 25th Penn Linguistics Colloquium, 71-85.

Boersma, P., \& Hayes, B. (1999). Empirical tests of the Gradual Learning Algorithm. Master's thesis, University of Amsterdam and UCLA.

Boersma, P., \& Hayes, B. (2001). Empirical tests of the Gradual Learning Algorithm. Linguistic Inquiry, 32, 45-86. 
International Journal of Applied Linguistics \& English Literature

ISSN 2200-3592 (Print), ISSN 2200-3452 (Online)

Vol. 1 No. 5; September 2012 [Special Issue on General Linguistics]

Bongaerts, T. (1999). Ultimate attainment in L2 pronunciation: The case of very advanced late learners. In D. Birdsong (Ed.), Second language acquisition and the Critical Period Hypothesis (pp. 133-159). NJ: Lawrence Erlbaum.

Bongaerts, T., Planken, B. \& Schils, E. (1995). Can late learners attain a native accent in a foreign language? A test of the critical period hypothesis. In D. Singleton \& Z. Lengyel (Eds.), The age factor in second language acquisition (pp. 30-50). Clevedon: Multilingual Matters.

Bongaerts, T., van Summeren, C., Planken, B., \&, Schils, E. (1997). Age and ultimate attainment in the pronunciation of a foreign language. Studies in Second Language Acquisition, 19, 447-465.

Broselow, E., \& Finer, D. (1991). Parameter setting in second language phonology and syntax. Second Language Research, 7, 35-59.

Chomsky, N. (1995). The minimalist program. Cambridge, MA: MIT Press.

Curtin, Suzanne (2001). Children's Early Representations: Evidence from Production and Perception.

Proceedings of the Holland Institute of Linguistics Phonology Conference (HILP 5), Potsdam, Germany.

Elliott, A. (1995). Field independence/dependence, hemispheric specialization, and attitude in relation to pronunciation accuracy in Spanish as a foreign language. Modern Language Journal, 79, 356-371.

Fathman, A. (1975). The relationship between age and second language productive ability. Language Learning, $25,245-253$.

Flege, J. (1987a). A critical period for learning to pronounce foreign languages? Applied Linguistics, 8, 162-177. Flege, J. (1987b). Effects of equivalence classification on the production of foreign language speech sounds. In A. James \& J. Leather (Eds.), Sound patterns in second language acquisition (pp. 9-40). Dordrecht: Foris. Flege, J. E. (1995). Second language speech learning: Theory, findings and problems. In W. Strange (Ed.), Speech perception and linguistic experience: Theoretical and methodological issues (pp. 233-277). Baltimore: York Press.

Flege, J. E., \& Eefting, W. (1987). Production and perception of English stops by native Spanish speakers. Journal of Phonetics, 15, 67-83.

Flege, J., \& Munro, M. (1994). The word unit in second language speech perception and production. Studies in Second Language Acquisition, 16, 381-411.

Grosjean, F. (1998). Studying bilinguals: Methodological and conceptual issues. Bilingualism: Language and Cognition, 1, 131-149.

Hancin-Bhatt, B. (2008). Second language phonology in Optimality Theory. In J.G.Hansen \& M. Zampini (Eds.), Phonology and second language acquisition (pp. 117-146). Philadelphia/Amsterdam: Benjamins. Ioup, G. (1989). Immigrant children who have failed to acquire native English. In S. Gass, C. Madden, D. Preston, \& L. Selinker (Eds.), Variation in second language acquisition, Vol. II: Psycholinguistic issues (pp. 160-175). Clevedon, UK: Multilingual Matters.

Klein, W. (1995). Language acquisition at different ages. In D. Magnusson (Ed.), The lifespan development of individuals: Behavioral, neurobiological and psychosocial perspectives. A synthesis (pp. 244-264). New york: Cambridge University Press.

Long, M. H. 2005. Problems with supposed counter-evidence to the critical period hypothesis. IRAL,

International Review of Applied Linguistics in Language Teaching 43(4), 287-317.

Long, M. H. 1990. Maturational constraints on language development. StudiesinSecondLanguageAcquisition 12(3), 251-285.

Lenneberg, E.H. (1967). Biological Foundations of Language. Wiley.

Major, R. (2001). Foreign accent: The ontogeny and phylogeny of second language phonology. Mahwah, NJ:

Erlbaum.

McCarthy, John. (1993). A case of surface constraint violation. In Carole Paradis et al., (Eds.), Constraint-based theories in multilinear phonology, a special issue of Canadian Journal of Linguistics.

Neufeld, G. (1978). On the acquisition of prosodic and articulatory features in adult language learning. The Canadian Modern Language Review, 34, 163-174.

Newport, E.L. (2002). Critical periods in language development. In L. Nadel (Ed.), Encyclopedia of Cognitive Science. London: Macmillan Publishers Ltd./Nature Publishing Group.

Novoa, L., Fein, D. and Obler, L. (1988). Talent in foreign languages: A case study. In L. Obler \& D.Fein (Eds.), The exceptional brain. Neuropsychology of talent and special abilities (pp. 294-302). New York: Guilford Press. Oyama, S. (1976). "A sensitive period for the acquisition of a nonnative phonological system". Journal of Psycholinguistic Research 5. 261-285. 
International Journal of Applied Linguistics \& English Literature

ISSN 2200-3592 (Print), ISSN 2200-3452 (Online)

Vol. 1 No. 5; September 2012 [Special Issue on General Linguistics]

Pater, J. (1993). Theory and methodology in the study of metrical parameter (re) setting. In J. Matthews \& L. White (Eds.), McGill Working Papers in Linguistics, 9, 211-243.

Prince, A. and Smolensky, P. (1993). Optimality Theory: Constraint Interaction in Generative Grammar.

Technical Report 2, Center for Cognitive Science, Rutgers University. Cambridge, MA: MIT Press.

Rothman, J. (2008). Why not all counter-evidence to the Critical Period Hypothesis in Second Language

Acquisition is not Equal or Problemantic. Language and Linguistics Compass 2(6). 1063-1088.

Rothman, J. and Guijarro-Furntes. (2010). Input Quality Matters: Some Comments on Input Type and

Age-Effects in Adult SLA.Applied Linguistics 31, (2). pp. 301-306.

Schneiderman and Desmarais (1988). The talented language learner. Some preliminary findings. Second language research 4, 91-109.

Schwartz, B. D. and Sprouse, R. A. (1994) Word order and nominative case in non-native language acquisition: A longitudinal study of (L1 Turkish) German interlanguage. In: Hoekstra T and Schwartz BD (eds) Language acquisition studies in generative grammar: Papers in honor of Kenneth Wexler from the 1991 GLOW workshops. Philadelphia, PA: John Benjamins, 317-68.

Schwartz, B. D. \& Sprouse, R. A. 1996. L2 cognitive states and the Full Transfer/Full Access model. Second Language Research 12, 40-72.

Scovel, T. (1981). The effects of neurological age on nonprimary language acquisition. In R. Andersen (Ed.), New dimensions in second language acquisition research (pp. 33-42). Rowley, MA: Newbury House.

Scovel, T. (1988). A Time to Speak: A Psycholinguistic Inquiry into the Critical Period for Human Language. Rowley, MA: Newbury House.

Selinker, L. (1972). Interlanguage. International Review of Applied Linguistics, 10, 209-231.

Singleton, D. (2005) The Critical Period Hypothesis: a coat of many colors. International Review of Applied Linguistics (IRAL) 43, 269-285.

Singleton, D. and Lengyel, Z. (1995). The Age Factor in Second Language Acquisition. Clevedon: Multilingual Matters.

Tesar, B. and Smolensky, P. (2000). Learnability in Optimality Theory. Cambridge, MA: MIT Press.

White, L. (2000). Second language acquisition from initial to final state. In J. Archibald (Ed.), Second language acquisition and linguistic theory (pp. 130-155). Oxford: Blackwell Publishers.

White, L. 2003. Second Language Acquisition and Universal Grammar. Cambridge: Cambridge University

Press.

White, L., \& Genessee, F. (1996). How native is near-native? The issue of ultimate attainment in adult second language acquisition. Second Language Research, 12, 233-265.

Wiltshire, C. (2005). The "Indian English" of Tibeto-Burman language speakers. English World-Wide, 26 (3), pp. 275-300.

Wode, H. (1989). Maturational changes of language acquisitional abilities. In S. Gass, C. Madden, D. Preston, \& L. Selinker (Eds.), Variation in second language acquisition, Vol. II: Psycholinguistic issues (pp. 176-188).

Clevedon, UK: Multilingual Matters.

Wode, H. (1992). Categorical perception and segmental coding in the ontogeny of sound systems. In C.

Ferguson, L. Menn, \& C. Stoehl-Gammon (Eds.), Phonological development: Models, research, implications (pp. 605-631). Timonium, MD: York Press.

Wode, H. (1993). The development of phonological abilities. In K. Hyltenstam \& A. Viberg (Eds.), Progression et regression in language (pp. 415-438). Cambridge:Cambridge University Press.

Wode, H. (1994). Introduction. L1 and L2 phonology: Looking ahead. In M. Yava $\square$ (Ed.), First and second language phonology (pp. 175-179). San Diego, CA: Singular.

Young-Scholten, M. (1994). On positive evidence and ultimate attainment in L2 phonology. Second Language Research, 10, 193-214.

Young-Scholten, M. (2002). "Orthographic input in L2 phonological development". In Burmeister, P.; Piske, T.; Rohde, A. An integrated View of Language Development: Papers in Honor of Henning Wode. Trier:

Wissenschaftlicher Verlag Trier. pp. 263-279.

Young-Scholten, M., \& Archibald, J. (2000). Second language syllable structure. In J. Archibald (Ed.) Second language acquisition and linguistic theory (pp. 64-101). Oxford, UK: Blackwell publishers. 